\title{
Tumor de piel de localización atípica: quiste epidérmico gigante perianal. Presentación de un caso
}

\author{
Gonzalo Castellano Egloff, ${ }^{1}$ Gustavo Nestares, ${ }^{2}$ Lorena Diez, ${ }^{3}$ Brian Santos ${ }^{3}$ \\ ${ }^{1}$ Encargado de la Unidad de Coloproctología. Clínica Adventista Belgrano. CABA, Argentina. \\ ${ }^{2}$ Jefe de Cirugía General. Clínica Adventista Belgrano. CABA, Argentina. \\ ${ }^{3}$ Médico Cirujano Staff. Clínica Adventista Belgrano. CABA, Argentina.
}

\begin{abstract}
RESUMEN
Introducción: Los quistes epidermoides son lesiones benignas de crecimiento lento que se originan a partir de la epidermis. Afectan en su mayoría a hombres jóvenes y adultos de mediana edad. Se presentan con más frecuencia en la cara, el cuello y el tronco, son atípicos en región perineal, extremidades, hueso y mama.

Caso clínico: Paciente masculino de 45 años, con tumoración perianal de 3 años de evolución. Refiere incomodidad al higienizarse y prurito. RMN informa lesión quística sin compromiso del canal anal. Exéresis completa del quiste con su cápsula. Informe anatomopatológico: quiste epidermoide. Control clínico sin recidivas.

Conclusión: Los quistes epidérmicos en región perianal son atípicos. Es de relevancia descartar otras patologías como absceso, quiste pilonidal hasta lesiones tumorales. La exéresis quirúrgica completa sin efracciones y con su cápsula es la regla a fin de evitar recidivas.
\end{abstract}

Palabras claves: Tumor perianal; Quiste epidermoide; Quiste epidérmico; Quiste infundibular; Quiste de inclusión; Quiste de queratina

\begin{abstract}
Epidermoid cysts are benign, slow-growing lesions that arise from the epidermis. They mainly affect young men and middleaged adults. They occur more frequently on the face, neck and trunk, being atypical in the perineal region, extremities, bones and breast. We present a 45-year-old man with a 3-year evolution perianal tumor that causes discomfort in hygiene and itching. Magnetic resonance imaging shows a cystic lesion without involvement of the anal canal. Complete excision was performed. It is important to rule out other conditions such as abscesses, pilonidal cyst, and neoplasms. Complete surgical excision of these lesions, without fractures and with their capsule, is the rule to avoid recurrences.
\end{abstract}

Keywords: Perianal Tumor; Epidermoid Cyst; Epidermal Cyst; Infundibular Cyst; Inclusion Cyst; Keratin Cyst

\section{INTRODUCCIÓN}

Los quistes epidermoides de inclusión son los quistes cutáneos más comunes. Estos pueden ocurrir en cualquier parte del cuerpo y se presentan con mayor frecuencia en la cara, el cuello y el tronco, siendo inusuales en región perineal, extremidades, hueso y mama. Se presentan como nódulos por debajo de la piel y habitualmente presentan un orificio central visible. ${ }^{1-3}$

Típicamente afectan a jóvenes y adultos de mediana edad, en su mayoría hombres, y pueden ocurrir debido a inflamación alrededor de los folículos pilosebáceos o debido a una implantación profunda en la epidermis por cirugía o lesión contusa o penetrante. ${ }^{4,5}$ Usualmente son asintomáticos, sin embargo, pueden inflamarse o infectarse y es inusual su transformación en malignidad. ${ }^{3,5}$

Los autores declaran ausencia de conflictos de interés.

Brian Uriel Santos

brian_uriel_santos@hotmail.com

Recibido: septiembre de 2020. Aceptado: noviembre de 2020.

\section{CASO CLÍNICO}

Paciente masculino de 45 años de edad que presenta tumoración perianal de 3 años de evolución. Dicha tumoración ha aumentado su tamaño en este periodo de tiempo y presenta incomodidad durante la higiene y prurito. No existe historia de cirugía o trauma del periné. Sus antecedentes personales revelan solo hipotiroidismo. E1 examen físico muestra una lesión situada en cuadrante anterolateral izquierdo, duroelástica, bordes netos, móvil, no adherida a planos profundos, no dolorosa a la palpación sin signos de complicación aguda (Figura 1). Estudio por imágenes, RMN: imagen nodular, redondeada, de bordes netos, señal homogénea, hiperintensa en T2 e intermedia en T1. Discretamente hiperintenso en difusión sin restricción significativa de ADC (Figura 2). Toma sutil contacto con MA del lado izquierdo, no involucra a los restantes componentes del canal anal. Mide 35 x $40 \mathrm{~mm}$ en plano axial y extensión cefalocaudal de $50 \mathrm{~mm}$. Procedimiento quirúrgico: anestesia ra- 


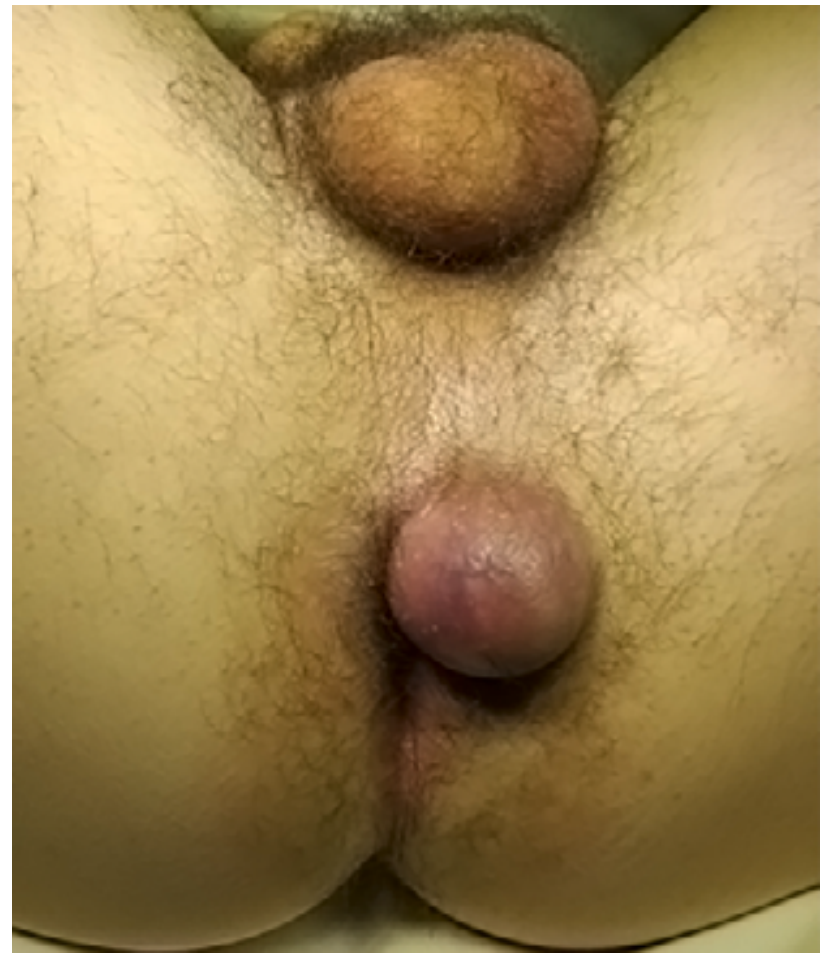

Figura 1: posición de litotomía, lesión en cuadrante anterior izquierdo sin compromiso del canal anal.

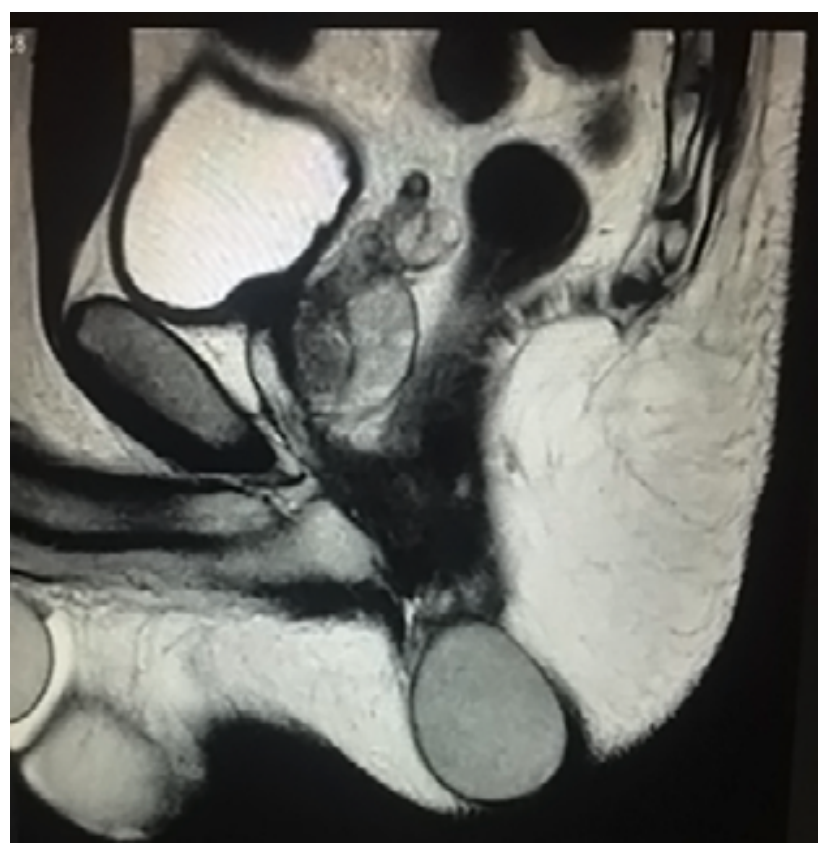

Figura 2: Imagen nodular, redondeada, de bordes netos y señal homogénea. Mide 35 x $40 \mathrm{~mm}$ en plano axial y extensión cefalocaudal de $50 \mathrm{~mm}$.

quídea, posición de litotomía, anoscopia sin evidencia de afectación del canal anal, incisión losangica sobre lesión, disección hasta pared del quiste y ectomía del mismo. Cierre del lecho quirúrgico con técnica semicerrada. Alta sanatorial a las $24 \mathrm{~h}$. Controles posquirúrgicos sin evidencia de recidiva.

Informe anatomopatológico: formación quística que

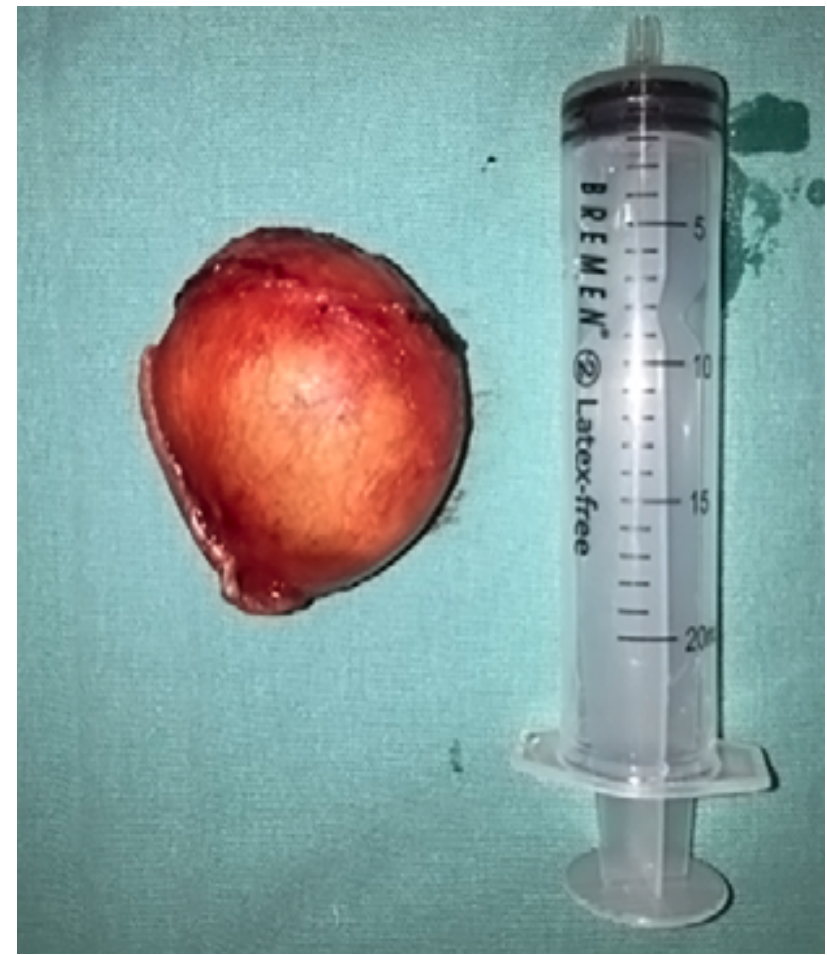

Figura 3: Formación quística que mide 4,5 x 1,5 cm.

mide 4,5 x 1,5 cm, compatible con quiste epidermoide (Figura 3).

\section{DISCUSIÓN}

Los quistes epidermoides son lesiones benignas de crecimiento lento que se originan a partir de la epidermis. Los mismos se generan como resultado de una proliferación de células epidérmicas dentro de la dermis, están revestidos por epitelio escamoso estratificado y rellenos de queratina.

Este tipo de quistes no suele presentar síntomas, pero pueden causar malestar debido al tamaño o si los mismos se infectan. Existen diversos factores que contribuyen a su formación incluyendo: la exposición a la luz UV, tabaquismo, HPV, pequeños traumatismos e inclusive procedimientos quirúrgicos como la episiotomía o biopsias con aguja fina. Son diagnósticos diferenciales: abscesos perianales, quiste pilonidal, quistes ductales/ glandulares, quistes "Tail Gut", teratomas benignos y tumores de ano o piel. La RMN es el estudio de elección para discriminar las diferentes lesiones de partes blandas y ayuda a establecer el diagnóstico correcto en casos de quistes epidermoides. Estos, se presentan típicamente como lesiones bien definidas, hipointensas en $\mathrm{T} 1$ e hiperintensas en T2. El refuerzo periférico es más evidente luego de la administración de contraste. La difusión confirma, además, el diagnóstico, estas lesiones muestran significativa 
restricción en la difusión. Una vez realizado el diagnóstico, la lesión debe ser extirpada con margen de seguridad. La pared completa del quiste debe ser removida para dis- minuir el riesgo de recidiva. El pronóstico de estas lesiones es excelente con una tasa de recurrencia de solo el $3 \%$ y con un riesgo de degeneración maligna infrecuente.

\section{REFERENCIAS}

1. Weir CB, St Hilaire NJ. Epidermal inclusion cyst. Stat pearls. Treasure Island (FL): Stat Pearls Publishing. 2020. Bookshelf ID: NBK532310PMID: 30335343.

2. Nicolay S, De Schepper A, Pouillon M. Epidermal inclusion cyst of the perianal region. JBR-BTR 2014;97:166-67.

3. Saeed U, Mazhar N. Epidermoid cyst of perineum: a rare case in a young female. BJR Case Rep 2017;2:20150352.

4. Lake ES, Engledow AH, Cohen CRG. An unusual perineal swelling: A cyst between the sphincters. J Surg Case Rep 2010;2010:2.

5. Sritharan K, Ghani Y, Thompson H. An unusual encounter of an epidermoid cyst. BMJ Case Rep 2014. doi: 10.1136/bcr-2014204186. 